\title{
Análisis del discurso en la Ley de Migración de México: ¿Qué se pretende con el procedimiento de presentación de extranjeros y el alojamiento en las estaciones migratorias?
}

Discourse Analysis of Mexico's Migration Law: Questioning the intention of the procedure for the presentation of foreigners and their accomodation at migratory stations?

Eduardo Gutiérrez López Universidad Autónoma de Baja California, México elias.gutierrez@uabc.edu.mx

\section{Resumen}

Este trabajo consiste en un análisis del discurso de la Ley de Migración (LM) [1], específicamente en lo relativo a la medida o procedimiento denominado presentación de extranjeros (PE), y al alojamiento en estaciones migratorias (AEM). La interpretación de los dispositivos legales que regulan a ambas figuras hará posible determinar la factibilidad de la hipótesis de que la intención de los legisladores mexicanos por producir un marco normativo incluyente, y sin un lenguaje que criminalice a los migrantes, se diluye frente a la predominación de ciertos elementos jurídicos y discursivos que cuando se analizan detalladamente, evidencian otro objetivo de estas normatividades.

Palabras clave: discurso, migración, extranjeros, derechos humanos, interpretación.

\begin{abstract}
:
This article analyzes discourses regarding Mexico's Migration Law (LM), specifically with regards to the procedure known as the presentation of foreigners (PE) and their accommodation at migratory stations (AEM). The interpretation of the legal instruments that regulate both concepts will enable us to determine the feasibility of the following hypothesis. It is proposed that the intentions of Mexican lawmakers to create an inclusive regulatory framework, without a language that criminalizes migrants, are diluted, given the predominance of certain legal and reflective elements, which, when analyzed in detail, demonstrate a different objective for these regulations.
\end{abstract}

Key words: discourse, migration, foreigners, human rights, interpretation. 


\section{Introducción}

En este trabajo se parte de la premisa de que los ordenamientos legales como componentes del derecho no deben concebirse exclusivamente como textos, sino también como elementos discursivos (Coaguila, 2005: 166; Villegas, 1993: 22)[2], sobre todo si estos forman parte de una política migratoria con una racionalidad, una postura y una finalidad concretas. La LM representa el marco discursivo -además de normativopor conducto del cual el Estado Mexicano comunica a instituciones, particulares, nacionales y extranjeros, la forma en que comprende al fenómeno migratorio, y por consiguiente, los métodos que habrá de operar para su regulación.

La PE y el AEM representan las medidas más determinantes con las que cuenta el Instituto Nacional de Migración (INM) (Diario Oficial de la Federación, 2011, artículo 20, fracción primera) para dar seguimiento a aquellos extranjeros que no tienen - en términos de la LM- una situación migratoria "regular" en México, a través de un procedimiento administrativo que busca, ya sea su deportación, o el retorno asistido. Lo llamativo de estas dos figuras son los términos lingüísticos que emplea: "presentación" y "alojamiento", que evocan significados que no necesariamente corresponden con los propósitos que se obtienen al realizar un análisis textual y contextual de la LM.

El objetivo de este trabajo es analizar el discurso de la $\mathrm{LM}$ en relación con los procedimientos de la $\mathrm{PE}$ y el AEM, y todo lo que se oculta tras el lenguaje que conforma a estas estructuras normativas. Se hará uso de la hermenéutica para la interpretación textual de estos dispositivos, estableciendo una comparación entre los discursos que configuran a estos mecanismos legales, y los relativos a la figura del arresto, para determinar sus grados de similitud. Finalmente se localizarán algunos conceptos jurídicos internacionalmente aceptados y que guarden conexión con estas medidas, para abonar a una comprensión integral de estos procedimientos contenidos en la legislación migratoria mexicana.

\section{2. ¿Qué son la PE y el AEM?}

En una primera pronunciación, el artículo $3^{\circ}$ fracción XX de la LM define a la PE como "la medida dictada por el Instituto mediante la cual se acuerda el alojamiento temporal de un extranjero que no acredita su situación migratoria..." (Diario Oficial de la Federación, 2011: 4). De este fragmento legal se desprende que la primera condición necesaria de la PE es el alojamiento temporal; sin embargo, un alojamiento se asocia más con una detención o un arresto, pues si la finalidad de esta medida fuera la sola presentación del extranjero ante la autoridad migratoria, no sería necesario el alojamiento. Ahora bien, si el alojamiento responde a una medida indispensable, ya que no se puede dejar "libre" a un extranjero que no reúna los requisitos de "regularidad migratoria", entonces esto significa 
que el extranjero sí está detenido, y si está detenido, no existiría justificación jurídica o lingüística para llamarle PE y no detención o arresto.

El AEM con motivo de la PE no puede exceder -según el artículo 68 de la LM- de un término de 36 horas (Diario Oficial de la Federación, 2011: 24). Estas 36 horas, además de ser la segunda condición de la PE, se asemejan a las que se asignan a las personas que se encuentran bajo arresto por una falta administrativa. A pesar de que el arresto es conceptualmente distinto a la prisión con motivo de la comisión de un delito, implica inexorablemente una detención y un alojamiento temporal (privación de la libertad): es decir, las mismas condiciones que se requieren para que opere la PE.

Para Castilla (2014: 173), el contenido del artículo 21 de la Constitución Mexicana es muy preciso en advertir que la única vía por la que una autoridad administrativa -como el INM-está facultada para privar de la libertad a una persona es por medio del arresto. Si la PE y el consecuente AEM no son un arresto, no hay razón legal alguna para que se les prive de la libertad a los migrantes, a menos que la LM estuviese creando una nueva figura no contemplada en la Constitución Mexicana para justificar la detención de estos migrantes. De ser así, y siguiendo la línea de Castilla (2014: 173), se estaría en presencia de una inconstitucionalidad, que para los propósitos analíticos de este trabajo se encuentra maquillada por un discurso inclusivo y garantista, pero que en el fondo reproduce una serie de símbolos y significados propios de una política que criminaliza a los migrantes en situación "irregular".

Los artículos 69 y 70 de la LM establecen la obligación de las autoridades migratorias de informar a quienes se encuentren sujetos al procedimiento de la PE acerca de sus derechos, los motivos de esta medida y la posibilidad de regularizar su situación migratoria, entre otras cuestiones, a la par que les confiere el derecho a ser representados legalmente y a contar con un debido proceso (Diario Oficial de la Federación, 2011: 24).

Si se considera preciso que la PE y el AEM sean clasificados como etapas de un procedimiento administrativo, se entenderían los motivos por los que toda esta información les sea obligatoriamente comunicada a los extranjeros sujetos a esta medida, ya que así lo delinea la Ley Federal del Procedimiento Administrativo en su artículo 70. Este último ordenamiento legal también enumera las sanciones a las que pueden hacerse acreedores quienes cometan una falta administrativa; una de estas sanciones consiste en el arresto por 36 horas (Diario Oficial de la Federación, 2017: 23-24). En este tenor, si un extranjero ingresa a territorio mexicano de manera "irregular" - de acuerdo a las leyes internas- y esto es considerado una falta administrativa, el arresto por 36 horas sería una forma lícita de sanción, pues así lo define el ordenamiento jurídico que regula a los procedimientos administrativos -como la PE-. Entonces, ¿Por qué no llamarle arresto? ¿Cuál es la pretensión de estas jiribillas lingüísticas en la LM?

Finalmente, los artículos 107 y 108 de la LM prevén los requisitos que deben cumplir las estaciones migratorias, que a decir verdad, tienen una relación directa con aquellos que deben reunir los centros penitenciarios de México. Para fines ilustrativos se presenta el siguiente cuadro comparativo: 
Tabla I

Consistencias entre los requerimientos de las estaciones migratorias y de los centros penitenciarios de México

\begin{tabular}{|c|c|}
\hline Estaciones migratorias & Centros penitenciarios \\
\hline Atención médica, psicológica y jurídica & $\begin{array}{l}\text { Asistencia médica preventiva y de tratamien- } \\
\text { to para el cuidado de la salud y que se ga- } \\
\text { rantice su integridad moral, física, sexual y } \\
\text { psicológica }\end{array}$ \\
\hline $\begin{array}{l}\text { Requerimientos alimentarios, ofreciendo tres } \\
\text { alimentos al día. El Instituto deberá supervi- } \\
\text { sar que la calidad de los alimentos sea ade- } \\
\text { cuada }\end{array}$ & $\begin{array}{l}\text { Alimentación nutritiva, suficiente y de cali- } \\
\text { dad, adecuada para la protección de su salud }\end{array}$ \\
\hline $\begin{array}{l}\text { Mantener en lugares separados y con medi- } \\
\text { das que aseguran la integridad física del ex- } \\
\text { tranjero, a hombres y mujeres }\end{array}$ & $\begin{array}{l}\text { Las mujeres compurgarán sus penas en luga- } \\
\text { res separados de los destinados a los hombres }\end{array}$ \\
\hline $\begin{array}{l}\text { Recibir un trato digno y humano durante toda } \\
\text { su estancia en la Estación Migratoria }\end{array}$ & $\begin{array}{l}\text { Recibir un trato digno del personal peniten- } \\
\text { ciario }\end{array}$ \\
\hline $\begin{array}{l}\text { No ser discriminado por las autoridades a } \\
\text { causa de su origen étnico o nacional, sexo, } \\
\text { género, edad, discapacidad, condición social } \\
\text { o; económica, estado de salud, embarazo, } \\
\text { lengua, religión, opiniones, preferencias se- } \\
\text { xuales, estado civil o cualquier otra circuns- } \\
\text { tancia }\end{array}$ & $\begin{array}{l}\text { Sin diferencias fundadas en prejuicios por } \\
\text { razón de género, origen étnico o nacional, } \\
\text { sexo, edad, discapacidades, condición social, } \\
\text { posición económica, condiciones de salud, } \\
\text { religión, opiniones, preferencias sexuales o } \\
\text { identidad de género, estado civil o cualquier } \\
\text { otra que atente contra la dignidad humana }\end{array}$ \\
\hline $\begin{array}{l}\text { Ser informado del motivo de su ingreso a la } \\
\text { estación migratoria y del procedimiento mi- } \\
\text { gratorio }\end{array}$ & $\begin{array}{l}\text { Ser informada de sus derechos y deberes, } \\
\text { desde el momento en que sea internada en el } \\
\text { Centro, de manera que se garantice el enten- } \\
\text { dimiento acerca de su situación }\end{array}$ \\
\hline $\begin{array}{l}\text { Permitir la visita de las personas que cumplan } \\
\text { con los requisitos establecidos en las disposi- } \\
\text { ciones jurídicas aplicables }\end{array}$ & Acceder al régimen de visitas \\
\hline
\end{tabular}

Fuentes: Diario Oficial de la Federación (2011 y 2016): Ley de Migración y Ley Nacional de Ejecución Penal. 
El contenido de esta la Tabla I permite concluir que las consistencias entre las condiciones que ambas legislaciones imponen para las estaciones migratorias y los centros penitenciarios obedecen a que la privación de la libertad se encuentra presente en los dos supuestos; esta privación se ha originado a través de una detención, independientemente de que la LM persista en llamarles presentación y/o alojamiento. Estas similitudes colocan en evidencia el trasfondo del discurso de la política migratoria en México, la que a través de un lenguaje afable criminaliza a los migrantes en situación "irregular" al conferirle a las estaciones migratorias los requerimientos como si se tratara de un centro penitenciario, al que por cierto sólo se accede a través de la comisión de un delito. Esto a pesar de que a partir de 2008 en México se despenalizó la migración indocumentada, al derogarse los artículos 119 al 124 de la Ley General de Población, para convertirla en una mera infracción de tipo administrativa.

\section{Análisis del discurso de la PE y el AEM}

Se debe precisar que se utilizará como marco de referencia la hermenéutica para el análisis del discurso de estas dos figuras legales. Los discursos, como formas de expresión del pensamiento, requieren de la hermenéutica para ser comprendidos e interpretados, ya que éstos se auxilian del lenguaje para manifestar un pensamiento individual o colectivo (Villegas, 1993:
20). En el ámbito jurídico, la hermenéutica ha sido empleada en base a la noción de que el derecho no representa únicamente un conjunto de reglas rígidas que se aplican de forma automatizada, sino que requiere de procesos constantes de interpretación y transformación para comprender con mayor claridad los actos humanos (Rodríguez, 2010: 324), pues como expresiones lingüísticas están sometidas a un devenir de sentido, y por lo regular, requieren de un acto de interpretación para vincular ese sentido a los hechos (Posada, 2010).

La LM, al igual que todos los ordenamientos legales federales en México, fue parte de un proceso legislativo debidamente prestablecido por la Sección II del Capítulo II del Título Tercero de la Constitución Política de los Estados Unidos Mexicanos (CPEUM). Asimismo, el artículo segundo de la LM dispone que este ordenamiento legislativo, en conjunto con su Reglamento, las normas secundarias y los programas de política pública, constituyen la política migratoria del Estado Mexicano (Diario Oficial de la Federación, 2011: 1). Tomando como referencia lo anterior, la LM simboliza la postura política de México ante el fenómeno de la migración en todas sus dimensiones.

Las políticas públicas en muchas ocasiones adoptan una razón instrumental -también denominada racionalidad-, por medio dela cual se busca la obtención de ciertos fines e intereses de carácter público, que por lo general, se distancian de consideraciones de orden moral (Canto, 2015: 260-261). Actualmente, en México persiste un debate en los ámbitos político y académico, 
sobre si la LM tiene una orientación de protección de los derechos humanos o de securitización. La pertinencia de este debate se basa en la creencia de que esta contienda traerá como resultado la interpretación más cercana hacia el verdadero propósito de la LM, y por ende, hacia la razón instrumental que enmarca su contenido. El conocimiento de la racionalidad de la LM como un componente de la política migratoria mexicana, sumará a la comprensión lingüística de la PE y el AEM como elementos discursivos y dotados de una finalidad concreta.

Las políticas migratorias de acuerdo a Mármora (1993 cit. en Jensen, 2010) representan el conjunto de propuestas institucionales que un Estado establece para la entrada, salida y/o permanencia de la población nacional y extranjera en su territorio (Instituto de Políticas Públicas en Derechos Humanos del MERCOSUR y Organización Internacional para las Migraciones, 2016:) [3]. Por su parte, dentro de estas políticas, predominan tres modelos de gobernabilidad migratoria: a) el de beneficios compartidos para países de origen y recepción; b) el de desarrollo humano para las migraciones; y c) el de securitización: este último tiene como eje la seguridad nacional y percibe al migrante como una amenaza, y en tal virtud opta por restringirle ciertos derechos -ya sea en lo legislativo o en lo pragmático- a partir de su irregularidad migratoria, la que hasta cierto punto se considera un sinónimo de ilegalidad (Mármora, 2010: 71-75).

A pesar de que la LM en su artículo $1^{\circ}$ determina que todas sus disposiciones se observarán dentro de un "marco de respeto, protección y salvaguarda de los derechos humanos..." (Diario Oficial de la Federación, 2011: 1), lo cierto es que también perdura una preocupación latente del Estado Mexicano por un tema de seguridad nacional, que no sólo queda expuesta en el contenido de este artículo, sino que se intensifica cuando se sabe de por medio que el INM se rige por la Ley General del Sistema Nacional de Seguridad Pública y se constituye como una de las instituciones federales mexicanas con mayores señalamientos por presuntas violaciones a derechos humanos (INEGI, 2016: 12). Esto permitiría deducir que la racionalidad o razón instrumental de la LM es la de proteger las fronteras, y por ende, la seguridad nacional.

Es oportuno referir que el 10 de junio de 2011, es decir, a poco más de un mes de que entrara en vigor la LM en México, la CPEUM sufrió una reforma relevante a su artículo $1^{\circ}$ que, entre otras cuestiones, confirma la obligación de todas las autoridades -en el ámbito de sus competencias- de promover, respetar, proteger y garantizar los derechos humanos de todas las personas en conformidad con los principios de universalidad, interdependencia, indivisibilidad y progresividad (Diario Oficial de la Federación, 2016: 2; Carpizo, 2011)[4]. Esta modificación constitucional produjo que la mayoría de las políticas, programas y legislaciones se adecuaran, o bien, fuesen diseñados a la luz de estos principios de los derechos humanos. Empero, la pregunta recurrente consiste en responder si el objetivo de estas adecuaciones implica una intención genuina del Estado Mexicano por respetar un marco de derechos humanos, o, si estas adaptaciones se utilizan 
como vanos compromisos políticos sin un trasfondo de viabilidad.

En términos migratorios esto ya ha sido trabajado por Domenech (2013: 121) al denominar políticas de control con rostro humano a aquellas prácticas que disfrazadas con un discurso de derechos humanos -para efectos de legitimidad-, tienen los mismos objetivos que las políticas abiertamente restrictivas o de securitización.

Para la "escuela" discursiva-contestataria de los derechos humanos [5], éstos se conceptualizan como meros discursos, en tanto que su fundamento se reduce a un hecho de lenguaje con carácter referencial (Arias, 2015: 15). A ello obedece en gran medida que los legisladores se apropien de esta postura y reproduzcan continuamente una visión de los derechos humanos cargada de una dosis discursiva, sin que forzosamente ésta dé cuenta de la realidad, pues finalmente el propósito es que esta idea sea adoptada por los receptores del mensaje, quienes a su vez la reproducirán, sin importar que no se presente una "correspondencia entre el desarrollo discursivo y normativo del proyecto de los Derechos Humanos y su situación práctica..." (Arias, 2015: 17).

A partir de estas nociones, y si se toma como base la propuesta de Villegas (1993: 37) de que la factibilidad en la comprensión e interpretación de un texto se encuentra en las condiciones de textualidad, cotextualidad y contextualidad, se puede analizar la LM y concretamente lo referente a la PE y el AEM como figuras insertas en su cuerpo normativo. Se le dará prioridad en este trabajo a la contextualidad, ya que esta condición se cree ha sido la más concluyente para influir en las decisiones que ha asumido el Estado Mexicano en la construcción y diseño de sus políticas y legislaciones en materia migratoria[6].

\section{Contexto migratorio en México previo a la entrada en vigor de la LM}

Para entender el contexto durante el que fue creada la LM, es preciso remembrar que la legislación que le antecedía en la regulación del fenómeno migratorio en México es la todavía vigente Ley General de Población (LGP) (Unidad de Política Migratoria, 2013: 84)[7]. Por no ser el objeto central de este texto, y sólo con fines explicativos, se subrayarán las principales diferencias entre ambos ordenamientos legales. La LGP como lo señala su artículo $1^{\circ}$, tiene como objeto "regular los fenómenos que afectan a la población en cuanto a su volumen, estructura, dinámica y distribución en el territorio nacional" (Diario Oficial de la Federación, 2015: 1). Es decir, su enfoque no es estrictamente migratorio -aunque si es uno de sus campos de regulación-, sino que abarca todas las aristas de los estudios de población -natalidad, mortalidad, migración-, por lo que era menester para México una ley especializada que pudiese regular todas las dimensiones que componen a la migración. 
Esta necesidad se sustenta en el hecho de que México ha dejado de ser únicamente un país expulsor de personas que llegan o intentan llegar a los Estados Unidos, ya que de a poco se ha ido consolidando como un país de tránsito para migrantes de Centroamérica y otros países que tienen ese mismo objetivo como lugar de destino. Asimismo, las múltiples deportaciones efectuadas por el gobierno de Estados Unidos han propiciado una migración de retorno al país, con características específicas y requerimientos jurídicos diferentes a otros tipos de migración. Estos puntos quedaron reflejados en la exposición de motivos de la LM, que de acuerdo a sus estimaciones, durante los 15 años anteriores a la entrada en vigor de este cuerpo normativo, se alcanzaron los 150 mil eventos por año de migración en tránsito en México, principalmente de centroamericanos (Salón de Sesiones del Senado de la República, 2010: 2). Por su parte, los datos de la Encuesta Nacional de la Dinámica Demográfica (ENADID) informaban de la duplicación del número de migrantes de retorno, al pasar de 289 mil a 562 mil desde el quinquenio de 1992-1997 al quinquenio de 2004-2009 (Ramírez y Aguado, 2013: 178).

Las implicaciones de estos informes estadísticos llevaronalEstado Mexicanoaconcluir sobrelo necesario de contar con una legislación que contemplara esta multidimensionalidad migratoria. Bajo esta tesitura, el artículo $2^{\circ}$ de la LM dispone cuáles son los principios sobre los que descansa la política migratoria mexicana, dentro de los que resalta el enfoque integral, que reside precisamente en la atención de cada una de las aristas que conforman las manifestaciones migratorias en
México (Diario Oficial de la Federación, 2011: 2).

Sin embargo, en la determinación de este principio, la LM nuevamente hace uso de posturas discursivas demagógicas con un alto grado de retórica, pero con poco sustento práctico y de viabilidad. Una prueba de esta afirmación es que a pesar del señalamiento del enfoque integral como principio rector de la política migratoria en México, es notorio el poco espacio que la LM le destina a la migración de retorno, al conferirle un pequeño párrafo en todo su contenido. Esto es paradójico, considerando el volumen de deportaciones de mexicanos en Estados Unidos, que justamente alcanzaron elevadas cifras durante la administración de Barak Obama, ya que ascendieron aproximadamente a 2.8 millones (Rentería, Rocha y Rodríguez, 2017: 9), sin pasar por alto las condiciones emergentes derivadas de estos procesos de deportación.

Una segunda evidencia es que el capítulo destinado a regular la migración en tránsito en México tampoco es de un tamaño adecuado, sobre todo si se toman en cuenta las reflexiones estadísticas descritas en la exposición de motivos de la LM y la notoria vulnerabilidad a la que son expuestos estos migrantes durante su estancia en el país (REDODEM, 2015)[8]. Esta fragilidad se refleja a través de los diferentes riesgos que experimentan durante su tránsito por México; estos consisten principalmente en las condiciones climáticas y peligros inherentes al transporte utilizado, inseguridad pública (hechos delictivos, violencia social) y violaciones a los derechos humanos derivadas del control migratorio (González y Aikin, 2015: 90). Tampoco deben pasar 
desapercibidos los informes publicados por la Comisión Nacional de los Derechos Humanos (CNDH) en 2009 y 2011, bajo los títulos "Informe especial sobre el caso de secuestros en contra de migrantes e Informe especial sobre secuestros de migrantes en México", en donde se documenta la participación de policías y agentes del INM en la comisión de violaciones a los derechos humanos de migrantes en México (Bustamante, 2013: 286).

La cantidad de artículos de la LM vinculados a la migración de retorno y a la migración de tránsito no es comparable con las cuantiosas estipulaciones sobre las formas de regularizar las condiciones de estancia para aquellos que cumplen con los requisitos para la residencia temporal o permanente, ni con los gruesos capítulos designados al control, verificación y revisión migratorios. Esta comparación permite ratificar lo sostenido en apartados anteriores, respecto a que la razón instrumental de la LM como parte sustantiva de la política migratoria mexicana es la seguridad nacional. De allí que, tratándose de migrantes en situación "irregular" o en tránsito por México, se haga hincapié en los diversos procedimientos de control y revisión por encima de la protección y salvaguarda de sus derechos humanos.

Con lo anterior no se quiere establecer una incompatibilidad entre ambas racionalidades ni descalificar a la seguridad nacional como una de las funciones estratégicas de cualquier Estado de derecho. Empero, lo cierto es que estos argumentos discursivos o lingüísticos pueden ser utilizados como herramientas autoritarias legitimadas para suspender ciertos derechos, o categorizar por encima de ellos, a la paz y a la seguridad de los ciudadanos, aprovechando algunos momentos críticos (García Ramírez y Morales, 2011: 12). Es por ello que la línea que hace dable la conjugación de la seguridad nacional y derechos humanos es muy sensible, y para mantenerla en equilibrio se necesita de una estructuración balanceada entre ambos propósitos, y con mayor razón para el Estado Mexicano, a partir de la inclusión del principio pro persona en la CPEUM (Pinto, 1997, p. 163) [9].

En la LM se puede apreciar una sobresaliente tendencia a priorizar la seguridad nacional como el eje central de todas las actuaciones de las autoridades migratorias. Para hacer más ilustrativa esta tendencia se presenta la siguiente tabla comparativa: 
Tabla 2

Seguridad nacional y derechos humanos: balance discursivo-normativo en la LM

\begin{tabular}{|c|c|c|}
\hline Racionalidad & $\begin{array}{l}\text { Artículos vinculados a su } \\
\text { regulación }\end{array}$ & Cantidad total de artículos \\
\hline Seguridad nacional & $\begin{array}{l}1,2,7,10,15,16,17,18,19, \\
20,23,26,31,32,33,34,35, \\
37,38,40,41,43,44,45,46, \\
47,48,50,52,53,54,57,59, \\
61,63,64,65,68,77,79,80, \\
81,82,83,84,86,87,88,90, \\
92,93,94,95,96,97,98,99, \\
100,102,103,104,105,106, \\
107,111,114,115,118,119, \\
121,126,127,128,129,130, \\
133,134,135,136,137,138, \\
142,144,145,146,152,154, \\
155,156,157,158,159,\end{array}$ & 92 \\
\hline Derechos humanos & $\begin{array}{l}1,2,6,8,9,11,12,13,14,22, \\
27,28,29,30,42,49,52,53, \\
54,55,56,58,60,62,66,67, \\
68,69,70,71,72,73,74,75, \\
76,77,78,89,90,101,106, \\
107,108,109,110,112,113, \\
116,117,119,120,122,123, \\
124,127,132,133,140,141, \\
148,159,160,161 .\end{array}$ & 63 \\
\hline
\end{tabular}

Nota: La forma de elección para la construcción de esta tabla se ha hecho a interpretación propia, tomando en consideración los elementos que componen a cada artículo de la LM. Los dispositivos relativos a la regularización migratoria, a través de las condiciones de residencia permanente o temporal, han sido concebidos como parte de un discurso de seguridad nacional, ya que es una forma por la cual el Estado Mexicano puede tener un control preciso de los migrantes por medio de los registros administrativos. Algunos artículos se han colocado en ambas categorías porque su contenido tiene relación con los dos tópicos propuestos en la tabla.

Fuente: Diario Oficial de la Federación (2011): Ley de Migración. 
Al profundizar en los resultados de la Tabla 2, es inevitable notar el desbalance entre ambas racionalidades y el predominio de la seguridad nacional como un cuadro que enmarca más de la mitad de los artículos -un $56.8 \%$ del contenido total- que integran la LM, mientras que aquellos que se conectan con aspectos de derechos humanos, solamente representan el 38.9\%. Este desbalance además de dejar en claro la razón instrumental del Estado Mexicano en materia de política migratoria, también puntualiza las debilidades de un aparato normativo y de gestión que ha llevado a que la Comisión Interamericana de Derechos Humanos (CIDH), en su informe "Derechos Humanos de los Migrantes en México" de 2014, haya enfatizado en la extrema vulnerabilidad de los migrantes y calificado a la situación como una tragedia humanitaria (Cornelio, 2015: 145).

\section{Interpretación jurídica de los procedimientos analizados}

Después de realizar una búsqueda en el Semanario Judicial de la Federación (SJF) de la Suprema Corte de Justicia de la Nación (SCJN), específicamente en la novena y décima épocas[10], no se encontraron criterios judiciales que aportaran a la comprensión integral de las figuras jurídicas estudiadas en este trabajo. En consecuencia, se optó por estimar la pertinencia de los diccionarios jurídicos latinoamericanos como punto de referencia para la interpretación de los conceptos presentación y alojamiento, y sus grados de similitud con el arresto.

De acuerdo a Cabanellas en su Diccionario Jurídico Elemental (2003: 317), se define a la presentación como la "comparecencia en un lugar", por consiguiente, al establecer como sinónimos a la presentación y a la comparecencia se vuelve menester remitir la atención hacia el concepto comparecer. Este verbo es delineado por el mismo diccionario de la siguiente manera: "parecer, presentarse uno personalmente o por poder ante otro, en virtud de una citación o requerimiento, o para mostrarse en algún asunto" (Cabanellas, 2003: 78). Acorde con estas definiciones, el término presentación -articulado en la LM-, desde una perspectiva jurídica, sólo tiene alcances conceptuales en lo referente a la presencia o comparecencia física de los extranjeros ante la autoridad migratoria, más no así, sobre algún tipo de detención o alojamiento, ya que esto conduciría el análisis hacia otro concepto, buscando ajustarlo de modo forzoso con lo que pretende la LM. Sin embargo, se produciría una distorsión del lenguaje jurídico, y más grave aún, una inconstitucionalidad manifiesta abrazada por un discurso aparentemente incluyente pero confuso.

Igualmente la Enciclopedia Jurídica Latinoamericana del Instituto de Investigaciones Jurídicas (IIJ) de la Universidad Nacional Autónoma de México (UNAM), entiende a la comparecencia como el "acto de concurrir ante alguna autoridad diversa de la judicial, para realizar una determinada actividad jurídica" (IIJ, 2006b: 397). En otras palabras, se puede afirmar 
que difícilmente se ubicarán diccionarios o textos jurídicos en donde se entrelace a la presentación con alguna clase de detención o alojamiento, porque son condiciones que no se encuentran necesariamente conectadas, ni depende una de la otra para conservar su raíz conceptual.

En lo que respecta al alojamiento, la citada enciclopedia del IIJ de la UNAM desmenuza el concepto ramificándolo en diferentes acepciones -ninguna de las cuales se refiere al tipo de alojamiento temporal que expone la LM-, tales como: el alojamiento de los trabajadores migratorios, de los trabajadores del campo, entre otros (IIJ, 2006a: 510). Empero, jamás se establece alguna tipología como la que se aborda en la LM, pues de todos estos modos de alojamiento previstos por esta enciclopedia, ninguno implica la existencia de estaciones migratorias, centros de detención, o cualquier otra modalidad denominativa en donde ineludiblemente exista una privación de la libertad.

En cambio, si se busca el arresto en las mismas fuentes enciclopédicas, éste se define como una "corta privación de la libertad que se realizará en lugar distinto del destinado al cumplimiento de las penas de privación de libertad, y cuya duración no debe exceder de 36 horas" (IIJ, 2006a: 530). Es notoria la similitud que guarda esta definición con las condiciones que la propia LM le confiere a la PE y al AEM, tales como la detención, el lugar distinto -que en este caso son las estaciones migratorias- y las multicitadas 36 horas. Es por ello que Castilla (2014: 172) ha insistido en que los términos presentación y alojamiento no son otra cosa sino simulaciones lingüísticas legales que significan la detención y la privación de la libertad perpetuadas por el INM. A manera de conclusión parcial, se presenta una tabla que resume estas reflexiones:

\section{Tabla 3}

\section{Cotejo entre los elementos que configuran el arresto y la PE}

\begin{tabular}{|l|l|}
\hline Arresto & PE \\
\hline Detención & "Presentación" ante la autoridad migratoria \\
\hline Privación de la libertad & Privación de la libertad \\
\hline Alojamiento en un centro de detención & Alojamiento en una "estación migratoria" \\
\hline 36 horas & 36 horas \\
\hline
\end{tabular}

Nota: La razón por las que algunas palabras se entrecomillan es porque la exposición de los argumentos en este trabajo ha evidenciado las verdaderas finalidades que se esconden tras estas simulaciones lingüísticas y discursivas.

Fuente: Elaboración propia con base en la LM (2011) y la Enciclopedia Jurídica Latinoamericana del IIJ de la UNAM (2006). 


\section{Consideraciones finales}

Después de haber interpretado el discurso del Estado Mexicano en lo concerniente a la PE y el AEM como medidas integrantes de la LM, por medio de herramientas analíticas textuales como la hermenéutica, y de haber sometido a discusión ambas figuras legales desde el plano conceptual y, particularmente, a la luz de comparaciones terminológicas con otras instituciones jurídicas, se dilucida que detrás del lenguaje empleado por los legisladores mexicanos para encausar a la LM hacia un enfoque de derechos humanos, respaldado por un discurso incluyente, se ocultan otros - tal vez, los verdaderos- propósitos de la política migratoria mexicana.

Estos propósitos se inscriben dentro de un paradigma de seguridad, que bajo el pretexto de proteger los intereses y derechos de los ciudadanos mexicanos, criminaliza a los migrantes, especialmente a quienes cataloga como "irregulares". Empero, derivado de los compromisos que el Estado Mexicano ha adquirido, con motivo de la suscripción y ratificación de variados tratados internacionales $-\mathrm{y}$ de sus propias limitaciones constitucionales-, no le es factible utilizar un discurso frontal y de disgusto por la inmigración y los inmigrantes. Es en este contexto que ha elegido deliberadamente usar estas jiribillas lingüísticas y legales para justificar discursivamente sus obligaciones internas e internacionales, pero pragmáticamente reproduciendo sus verdaderas finalidades políticas.
Estas finalidades, al ser traducidas por los mecanismos de interpretación textual y contextual, dan como resultado la poca hospitalidad de México -al menos legalmente- ante los inmigrantes, principalmente hacia aquellos que no pueden adherirse a ningún tipo de visa o categoría de residente temporal o permanente. Persiste pues, una visión de calificar a los inmigrantes como sospechosos por excelencia (Martínez, 2013: 15), tras el argumento retórico de la seguridad nacional. Esta visión de sospecha frente a la otredad es el primer paso para la criminalización; de allí que la PE y el AEM se asemejen conceptualmente tanto a figuras como al arresto y conlleven de por medio la detención, y por ende, la privación de la libertad o que los requerimientos para las estaciones migratorias se parezcan tanto a los impuestos para los centros penitenciarios.

En conclusión, la LM no es incluyente ni amistosa frente al fenómeno migratorio, al menos no con quienes se encuentran en situación de "irregularidad". Los dispositivos relativos a la PE y al AEM son pruebas consistentes de esta hipótesis. La razón instrumental de la LM, y en general, de la política migratoria en México está asociada con la criminalización, el temor infundado y los prejuicios, y no así con los derechos humanos, a pesar de que su discurso pretenda decir lo contrario. En otras palabras, aquellos migrantes que no reúnan los requisitos legales previstos por la LM, no solamente no son bienvenidos al país, sino que sus derechos humanos no representan una prioridad para el Estado Mexicano, y por consiguiente, se les "presentará" y "alojará" hasta que puedan ser devueltos a sus países de origen. 


\section{Bibliografía}

Arias, A. (2015): “Tesis sobre una teoría crítica de los derechos humanos”, Open Insight, 6(9), pp. 11-33.

Bustamante, J. (2013): "La "responsabilidad de Estado" y las migraciones internacionales", en M. Anguiano y R. Cruz, coords., Migraciones internacionales, crisis y vulnerabilidades. Perspectivas comparadas, México, El Colegio de la Frontera Norte, pp. 285-320.

Cabanellas, G. (2003): Diccionario Jurídico Elemental, Buenos Aires, Heliasta.

Canto, R. (2015): "Políticas públicas, racionalidad y razón”, Tópicos, Revista de Filosofía, 49, pp. 259-290.

Carpizo, J. (2011): Los derechos humanos: naturaleza, denominación y características, Cuestiones constitucionales, Revista Mexicana de Derecho Constitucional, 25, pp. 3-29.

Castilla, K. (2014): "Ley de Migración mexicana: Algunas de sus inconstitucionalidades", Migración y desarrollo, 23, pp. 151-183.

Coaguila, J. (2005): "El análisis discursivo del derecho", Isonomía, 23, pp. 165-177.

Cornelio, R. (2015): "Los derechos humanos de los inmigrantes de la frontera sur de México", Barataria, 19, pp. 139-150.

Diario Oficial de la Federación (2011): Ley de Migración, edición actualizada. Disponible en web: http://www.diputados.gob.mx/LeyesBiblio/pdf/LMigra 190517.pdf [Consulta: 12 de agosto de 2017].
Diario Oficial de la Federación (2015): Ley General de Población, edición actualizada. Disponible en web: http://www.diputados.gob.mx/LeyesBiblio/pdf/140 011215.pdf [Consulta: $23 \mathrm{de}$ agosto de 2017].

Diario Oficial de la Federación (2016): Constitución Política de los Estados Unidos Mexicanos, edición actualizada. Disponible en web: http://www.diputados.gob.mx/LeyesBiblio/ pdf/1 150917.pdf [Consulta: 15 de agosto de 2017].

Diario Oficial de la Federación (2017a): Ley Nacional de Ejecución Penal. Disponible en web: http://www.diputados.gob.mx/LeyesBiblio/pdf/ LNEP.pdf [Consulta: 15 de agosto de 2017].

Diario Oficial de la Federación (2017b): Ley Federal del Procedimiento Administrativo, edición actualizada. Disponible en web: http://www.diputados.gob.mx/LeyesBiblio/pdf/112 020517. pdf [Consulta: 18 de agosto de 2017].

Domenech, E. (2013): "'Las migraciones son como el agua': Hacia la instauración de políticas de 'control con rostro humano'. La gobernabilidad migratoria en la Argentina", Polis, Revista Latinoamericana, 12(35), pp. 119-142.

García Ramírez, S. y J. Morales (2011): La reforma constitucional sobre derechos humanos (2009-2011), México, Editorial Porrúa, Universidad Nacional Autónoma de México.

González, A. y O. Aikin (2016): “Migración de tránsito por la ruta del occidente de México: actores, riesgos y perfiles de vulnerabilidad", Migración y desarrollo, 24, pp. 81-115.

Instituto de Investigaciones Jurídicas, IIJ (2006a): Enciclopedia Jurídica Latinoamericana, Tomo I, México, Editorial Porrúa, UNAM. 
Instituto de Investigaciones Jurídicas, IIJ (2006b): Enciclopedia Jurídica Latinoamericana, Tomo II, México, Editorial Porrúa, UNAM.

Instituto de Políticas Públicas en Derechos Humanos del MERCOSUR y Organización Internacional para las Migraciones (2016): Migración, derechos humanos y política migratoria, Instituto de Políticas Públicas en Derechos Humanos del MERCOSUR y Organización Internacional para las Migraciones (OIM).

Instituto Nacional de Estadística y Geografía, INEGI (2016): Estadísticas de los Derechos Humanos en México desde los Organismos Públicos encargados de su protección y defensa, 2013, México, INEGI.

Jensen, M. F. (2010): "Inmigrantes en Chile: la exclusión vista desde la política migratoria chilena", Serie Investigaciones No. 7 ALAP, Río de Janeiro, Ediciones Trilce.

Mármora, L. (2010): "Modelos de gobernabilidad migratoria. La perspectiva política en América del Sur", Brasília, Revista Interdisciplinar da Mobilidade Humana, 18(35), pp. 71-92.

Martínez, C. (2013): “La violación de los derechos humanos de los migrantes irregulares. Un análisis a través del enfoque del estado de excepción de Giorgio Agamben", Dignitas, 23, pp. 13-35.

Pinto, M. (1997): "El principio pro homine . Criterios de hermenéutica y pautas para la regulación de los derechos humanos”, en Abregú, M. y Ch. Courtis, comps., La aplicación de los tratados sobre derechos humanos por los tribunales locales, Buenos Aires, Centro de Estudios Legales y Sociales, Editores del Puerto, pp. 163-171.
Posada, J. (2010): Elementos fundamentales de la hermenéutica jurídica, Nuevo Derecho, 5(6), pp. 47-63.

Ramírez, T. y D. Aguado, (2013): "Determinantes de la migración de retorno en México, 20072009”, en La situación demográfica de México 2013, México, Consejo Nacional de Población., pp. 175-190.

Red de Documentación de las Organizaciones Defensoras de Migrantes, REDODEM (2015): Migración en tránsito por México: rostro de una crisis humanitaria internacional, Catholic Relief Services, Entreculturas.

Rentería, V., D. Rocha y J. Rodríguez (2017): "Asimilación e integración social: un estudio de caso en menores migrantes de retorno asentados en ciudades fronterizas del norte de México", Región y sociedad, 29(69), pp. 5-29.

Rodríguez, M. J. (2010): Métodos de interpretación, hermenéutica y derecho natural, Dikaion, 19(2), pp. 319-347.

Salón de Sesiones del Senado de la República (2010): Iniciativa con proyecto de decreto por el que se expide la ley de migración y se reforman, derogan y adicionan diversas disposiciones de la ley general de población, de la ley aduanera, de la ley federal de derechos, del código penal federal, del código federal de procedimientos penales, de la ley federal contra la delincuencia organizada, de la ley de la policía federal, de la ley de asociaciones religiosas y culto público, de la ley de inversión extranjera, de la ley general de turismo y de la ley de comercio exterior. Disponible en web: http://sil.gobernacion.gob.mx/ Archivos/Documentos/2010/12/asun_2721389 20101209 1291911767.pdf [Consulta: 25 de agosto de 2017]. 
Unidad de Política Migratoria (2013): La protección de los Derechos Humanos de las personas migrantes: una guía para las y los servidores públicos, México, Unidad de Política Migratoria, Instituto Nacional de Migración, Alto Comisionado de Naciones Unidas para los Derechos Humanos.

Villegas, M. (1993): "Las disciplinas del discurso: hermenéutica, semiótica y análisis textual”, Anuario de Psicología, 59, pp. 19-60.

Recibido: 30 de octubre de 2017

Aceptado: 29 de diciembre de 2017

\section{NOTAS}

[1] La LM fue publicada el 25 de mayo de 2011 en el Diario Oficial de la Federación, y entró en vigor en México un día después de su publicación. Esta ley representa un elemento toral de la política migratoria mexicana en lo relativo a la migración internacional.

[2] El discurso, a diferencia del texto, se enfoca en la relación que nace entre el emisor y el receptor, pues implica una serie de procesos de producción y comprensión del mensaje. Las leyes u ordenamientos legales generan esta clase de procesos, y no es novedad que la hermenéutica haya sido utilizada en las interpretaciones judiciales de los textos jurídicos.

[3] Esta misma definición ha sido recuperada por la Corte Interamericana de Derechos Humanos en la Opinión Consultiva OC-18/03 titulada "Condición jurídica y derechos de los migrantes indocumentados".
[4] Para Carpizo, la universalidad implica que todo ser humano cuenta con una serie de derechos, con independencia de cuál sea su país de nacimiento o de residencia; la indivisibilidad radica en que todos los derechos, sean civiles, políticos, económicos, sociales, culturales o de solidaridad forman una unidad, de tal manera que poseen una interdependencia entre sí que les permite coadyuvar para conseguir esa unidad; la progresividad consiste en una ampliación irreversible de la protección nacional, regional e internacional de los derechos.

[5] Para Arias existen cuatro conceptualizaciones principales sobre los derechos humanos: la naturalista (ortodoxia tradicional); la deliberativa (nueva ortodoxia); la de protesta (de resistencia) y la discursiva-contestataria (disidente, nihilista).

[6] Gran parte de estos puntos contextuales, que sirvieron de base para incidir en el producto final de la LM, se encuentran en la exposición de motivos de la iniciativa de ley de este conjunto normativo.

[7] Existieron otros antecedentes en la regulación migratoria, como la Ley de Inmigración de 1909 y la Ley de Migración de 1926 y 1930

[8] De acuerdo a la información de la base de datos de la Red de Documentación de las Organizaciones Defensoras de Migrantes, en 2015 1,768 migrantes manifestaron haber sido víctimas de algún delito en México, de los cuales, sus tres principales nacionalidades fueron: hondureños con un $52 \%$, salvadoreños con un $23.22 \%$ y guatemaltecos con un $14.82 \%$; asimismo, los delitos más comunes en contra de estos migrantes fueron el robo y la extorsión, cometidos en gran medida por el crimen organizado y algunas autoridades de distintos niveles de gobierno. 
[9] También llamado principio pro homine y definido como un "criterio hermenéutico que informa todo el derecho de los derechos humanos, en virtud del cual se debe acudir a la norma más amplia, o a la interpretación más extensiva...".

[10] En México, los criterios de jurisprudencia se encuentran ordenados y sistematizados por épocas. Para efectos de este trabajo, se ha demarcado la búsqueda sólo en la novena y décima épocas, puesto que la LM entró en vigor en 2011. 